\title{
Indicators of Browsing Pressure Suggest Constraints on Riparian Willows: A Case Study From the Bighorn National Forest, Wyoming
}

\author{
By Michael R. Bower, Luke A. Decker, Amy L. Nowakowski, and Chris L. Williams
}

\section{On the Ground}

- We completed a landscape-scale assessment of ungulate browsing pressure on the southeastern portion of the Bighorn National Forest and found evidence of constraints on willow morphology and height.

- To better understand these apparent constraints over time and to enable adaptive habitat management, we propose development of a willow monitoring scheme based on an experimental design that controls for site potential and isolates the contributions of individual ungulate species to total willow browse.

- Further investigating the current status of riparian willows in terms of population vital rates and future distribution trends could be particularly important to help determine the cause of a recent decline in beaver abundance.

Keywords: riparian willow, herbivory, browsing pressure, ungulates, beaver, cascading ecosystem effects, riparian ecosystem state, Bighorn Mountains, Wyoming.

Rangelands 36(6):22-30

DOI: 10.2111/RANGELANDS-D-14-00012.1

(C) 2014 The Society for Range Management

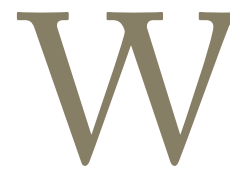
illows (Salix spp.) are important components of terrestrial and aquatic ecosystems. Willows are valuable forage for a variety of species, such as moose (Alces alces), elk (Cervus elaphus), beaver (Castor canadensis), and domestic livestock. Where willows grow to reach their full potential stature, they can serve as important cover habitats for a va- riety of mammals and birds. Along stream courses, woody riparian plants such as willows help protect stream banks from erosion; provide shade, which can moderate summer water temperatures; and make substantial contributions to aquatic food webs.

Widespread declines of riparian willow communities have been reported in several areas of the Rocky Mountains over the past two decades, including prominent protected areas such as Yellowstone National Park and Rocky Mountain National Park, spurring concern for the status of this habitat type. These declines have frequently been attributed to increasing ungulate herbivory, though factors such as changing climatic or hydrologic conditions and diseases have also been implicated.

Cascading ecosystem effects that influence long-term willow recovery potential have also accompanied observed declines. For example, in Yellowstone National Park, suppression of willow height by elk is thought to have resulted in the local extirpation of beaver. Abandonment of sites by beaver can initiate a negative feedback on willow reproduction and recruitment as the positive effects of dam construction activities on the hydrological conditions needed for successful seedling establishment and survival diminish over time. In some landscapes, it appears that this negative feedback loop can cause ecosystems to revert to an alternative stable state characterized by limited willow recruitment and a greater proportion of upland habitats. Such systems may lack a mechanism to regain positive willow seedling establishment and growth conditions, leading some to suggest willow planting and exclusion of ungulate browsers or stream channel restoration to mimic the hydrologic effects of beaver dams in order to restore willow recovery potential. Additional references describing the roles of riparian willows in terrestrial and aquatic ecosystems and recent work to understand factors affecting their status in the Rocky Mountain region, as summarized in preceding paragraphs, are proved as 

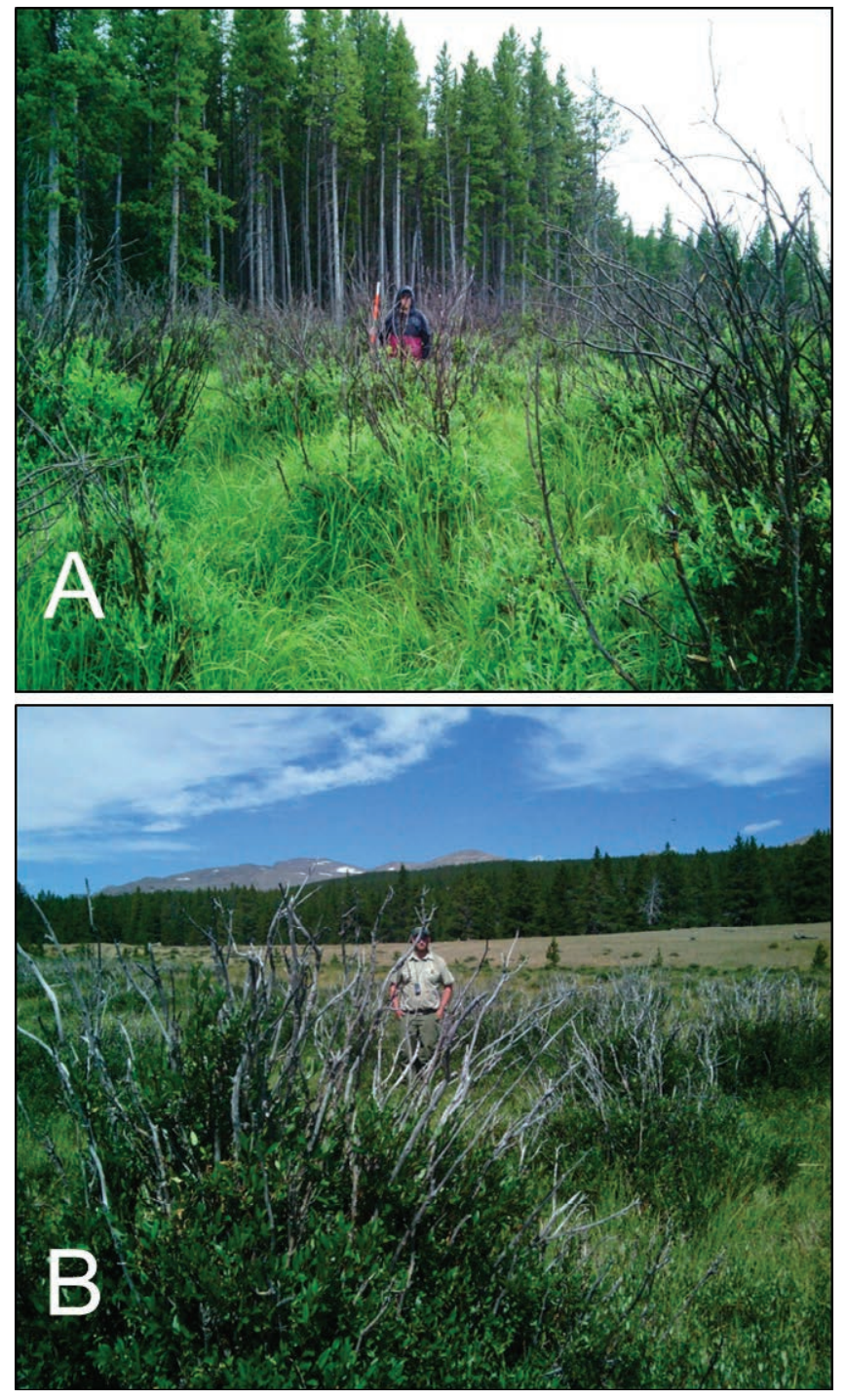

Figure 1. Examples from sampling sites $\mathbf{A}, 30$ and $\mathbf{B}, 49$ of two areas exhibiting signs of willow dieback during 2012. Note the crown of dead stems extending above the live stems. Such observations have spurred concern that this habitat type may be declining on portions of the Bighorn National Forest.

online supplemental materials at http://dx.doi.org/10.2111/ Rangelands-D-14-00012.s1.

The Bighorn National Forest (BNF) of north-central Wyoming is a multiple-use landscape that includes a variety of riparian ecosystems and associated willow communities supporting diverse fish and wildlife populations of regional importance. Anecdotal observations from the southern portion of the BNF, including documentation of areas exhibiting signs of willow dieback (i.e., where a crown of dead stems is visible in many plants; Fig. 1), have caused concern for the local status of riparian willow communities in the Bighorn Mountains. Given that willow declines in the Rocky Mountains have oftentimes been attributed to ungulate herbivory, we assessed indicators of recent browsing pressure as the first step toward understanding factors affecting willow status on a portion of the BNF. Our assessment included two phases: 1) a landscape-scale survey of dominant shrub shapes or architectures, based on known responses to varying levels of ungulate herbivory, to characterize broad patterns of browsing pressure and 2) additional direct measures of recent willow height gain following browsing to assess willow growth and recruitment potential. We further consider how several factors may explain observed patterns and describe how additional monitoring and research could help enable adaptive habitat management. Finally, we project the potential implications of our findings for management of riparian ecosystems and keystone species such as beaver.

\section{Assessing Indicators of Ungulate Browsing Pressure}

Our study area included the majority of the southeastern portion of the BNF (Fig. 2). Within this area, 50 random sampling points were established in potential willow vegetation types. Forty-two of these sites were visited during the summer and fall of 2012 to characterize dominant shrub architectures, as an indication of ungulate browsing pressure. The remaining eight sites were not visited because of poor accessibility and time constraints. Observers navigated to random sampling point coordinates using a global positioning system (GPS) receiver. In the event that there were no willows within $9.17 \mathrm{~m}$ of the location, but willows were present nearby, observers established a new sampling point $9.17 \mathrm{~m}$ beyond the nearest willow, in a straight line from the original point, and coordinates were updated to the new sampling location. Circular sampling plots with a radius of $9.17 \mathrm{~m}$ were established at each site. Most sampling locations were documented with four pictures, one facing each of the four cardinal directions, as determined by compass bearing.

Within each sampling plot, observers determined the dominant browsing-related architecture for each of four height-classes: $0-50 \mathrm{~cm}, 50-150 \mathrm{~cm}, 150-250 \mathrm{~cm}$, and $>250$ $\mathrm{cm}$, as in Keigley et al. ${ }^{1}$ The four browsing-related architectures were 1) "uninterrupted," produced under light-moderate browsing conditions; 2) "arrested," produced by intense browsing; 3) "retrogressed," produced by a change from light or moderate browsing to intense browsing; and 4) "released," produced by a change from intense browsing to light or moderate browsing (Fig. 3). Rather than focusing on a single indicator species, a separate rating was completed for each willow species present to help inform the development of future monitoring programs and to better characterize the status of the riparian willow community at large.

During the summer and fall of 2013, 16 of the 42 sites were revisited to complete more direct measures of recent height growth following browsing based on the "live-dead index" (LD index), of Keigley et al. ${ }^{2}$ Sites were selected for sampling opportunistically, based primarily on accessibility. As above, GPS navigation was used to return to the general location of sampling sites surveyed in 2012. Given potential GPS inaccuracies, we did not assume that we had returned to 


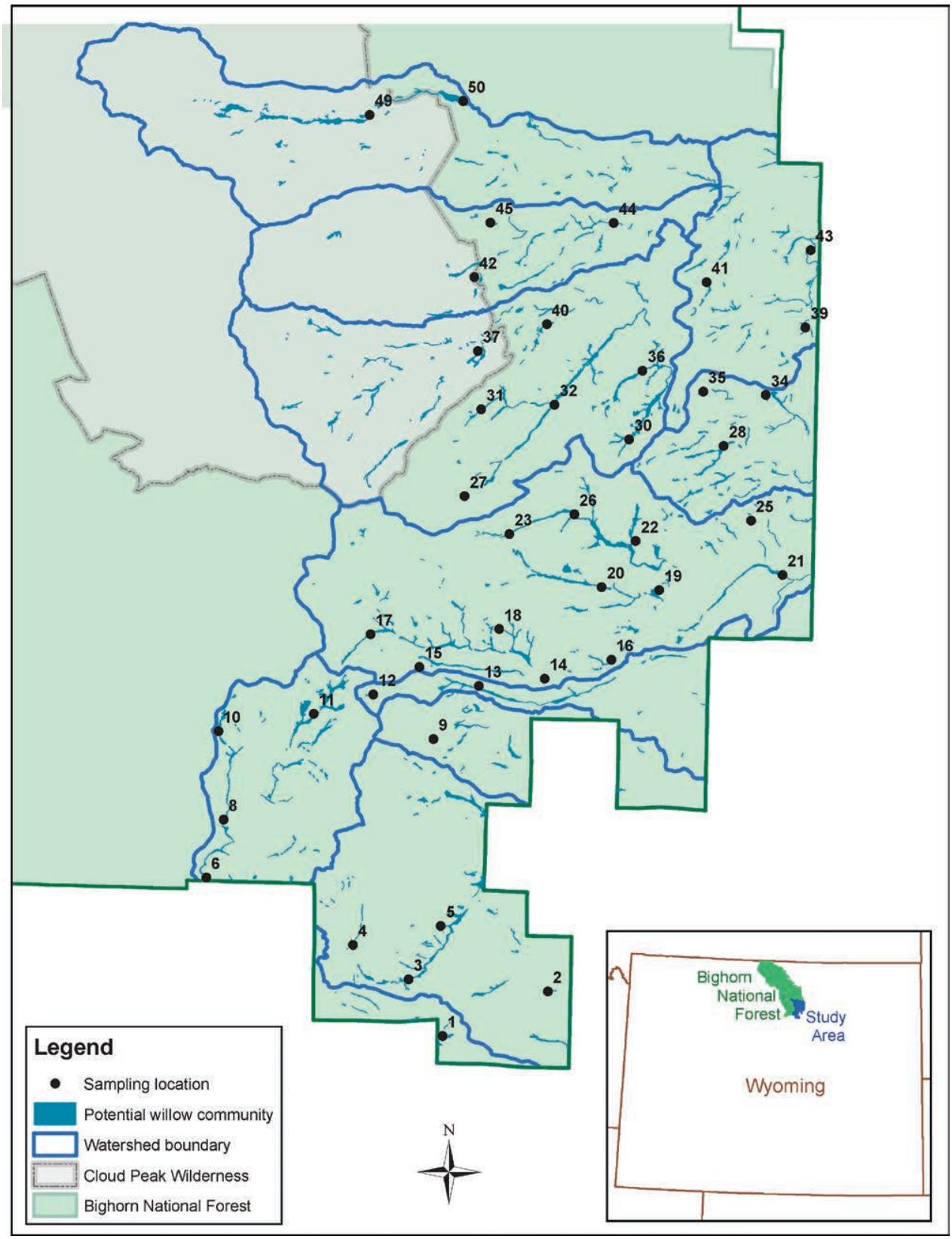

Figure 2. Map depicting the study area on the southeastern portion of the Bighorn National Forest, Wyoming, and final sampling locations from 2012 and 2013 within study area watersheds.

the precise location of former sampling. Line transects of sufficient length to enable sampling of 20 willow plants, spaced $5 \mathrm{~m}$ apart, were established at each site. In general, transects ran in a straight line, although in some cases transect course was adjusted to stay within narrow willow habitats. Sampled plants were limited to those in the $50-150 \mathrm{~cm}$ height class or to those in the $<50 \mathrm{~cm}$ height class that had been "intensely browsed," as suggested by Keigley et al., ${ }^{2}$ to ensure that sampled plants were available to be browsed by ungulates (i.e., taller plants extend above the ungulate browse zone and shorter plants may be protected by snow for a portion of the year). Additional factors that could affect ungulate access, such as the presence of any mechanical protection or local aspect and topography that could influence snow depth, were noted. We sampled each willow plant meeting the above criteria, regardless of species.

For each sampled willow plant, two measurements were made: the height above ground level of the tallest live leader as measured to the base of the current year's growth $\left(\mathrm{H}_{\mathrm{PYG}}\right)$ and the height above ground level to the tip of the tallest stem having a dead, vertically oriented, complete annual increment that was browsed $\left(\mathrm{H}_{\mathrm{D}}\right)$. $^{2}$ The base of the current year's growth was used as the measurement target to control for variation in the timing of annual browsing and stem growth. The LD 


\section{Browsing-related Architectures of Shrubs}

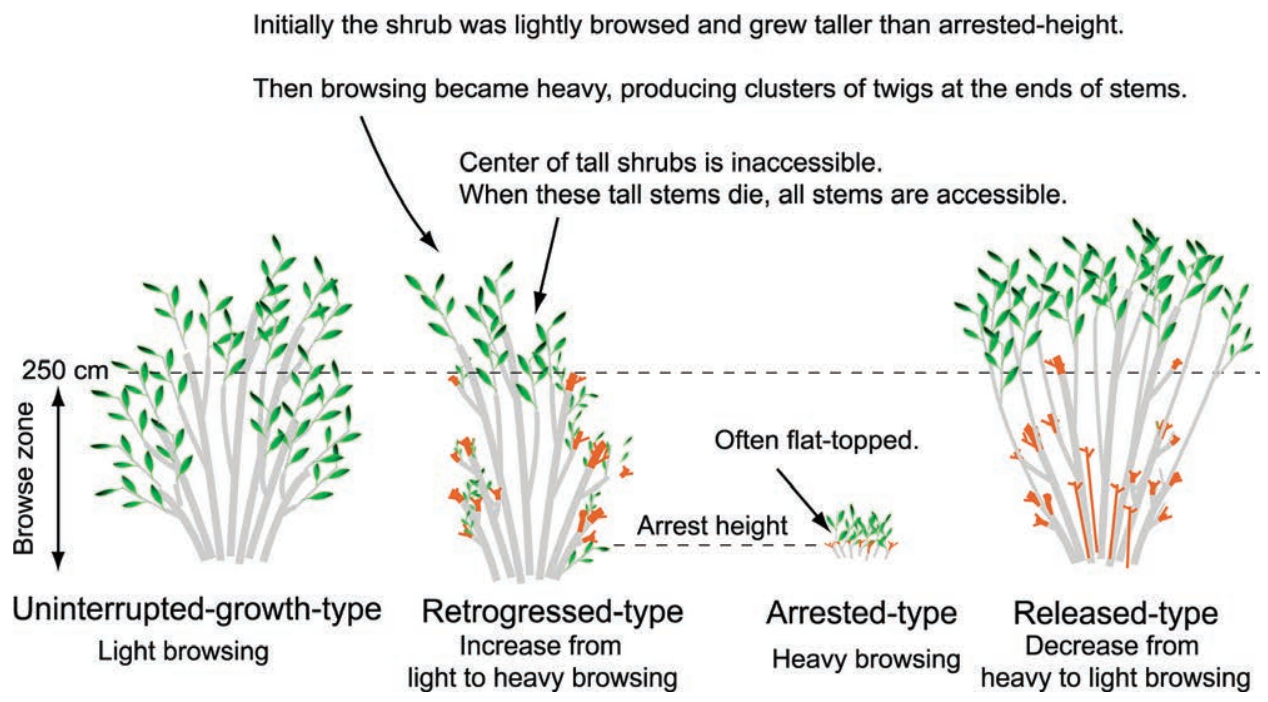

Figure 3. The four architecture types of shrubs, as in Keigley et al. ${ }^{1}$

index was computed as $\mathrm{H}_{\mathrm{PYG}}-\mathrm{H}_{\mathrm{D}}$ for each sampled plant. Mean LD index and the percentage of plants with LD index values $<50 \mathrm{~cm}$ (i.e., the "existing browsing pressure" of Keigley and Frisina ${ }^{3}$ ) were computed for each site to enable comparisons to prior work. LD index values near zero are indicative of browsing of current-year growth to the level of mechanical protection afforded by dead stems and twigs, thus preventing height growth. Where LD index values are substantially less than zero, plants are losing height or dying back to ground level. Values greater than zero indicate that plants have gained height after having been browsed. ${ }^{3}$

Agency records of wild and domestic ungulate abundance were compiled to enable comparisons with observed architectures and LD index scores. The nonparametric Mann-Kendall test was used to investigate significant abundance trends over the period of record. Additional detailed descriptions of the study area, sampling design, and analysis of ungulate abundance are provided as online supplemental materials (available at http://dx.doi.org/10.2111/Rangelands-D-14-00012.s1).

\section{Results Suggest Browsing Effects and Recent Height Loss}

Willows were present in the vicinity of 39 of 42 sites visited during 2012. Dominant architecture types varied by height class (Fig. 4). The dominant architecture type in the 0-50$\mathrm{cm}$ size class was characterized as arrested $100 \%$ of the time, regardless of species. Within the $50-150-\mathrm{cm}$ height class, dominant architectures included both arrested and retrogressed types. The dominant architecture types within the 150-250-cm height class were either arrested or retrogressed, with one exception at a single site where the dominant architecture was characterized as the released type. Within the $>250-\mathrm{cm}$ height class, dominant architecture types were a combination of retrogressed and released types.
A key assumption of the architecture-type survey approach of Keigley et al., ${ }^{1}$ is that surveyed plants have the potential to respond morphologically to ungulate browsing. The maximum height-growth potential of planeleaf willow (Salix planifolia) is thought to vary among two forms found on the BNF. Girard et al. ${ }^{4}$ identified two varieties: planeleaf wil-

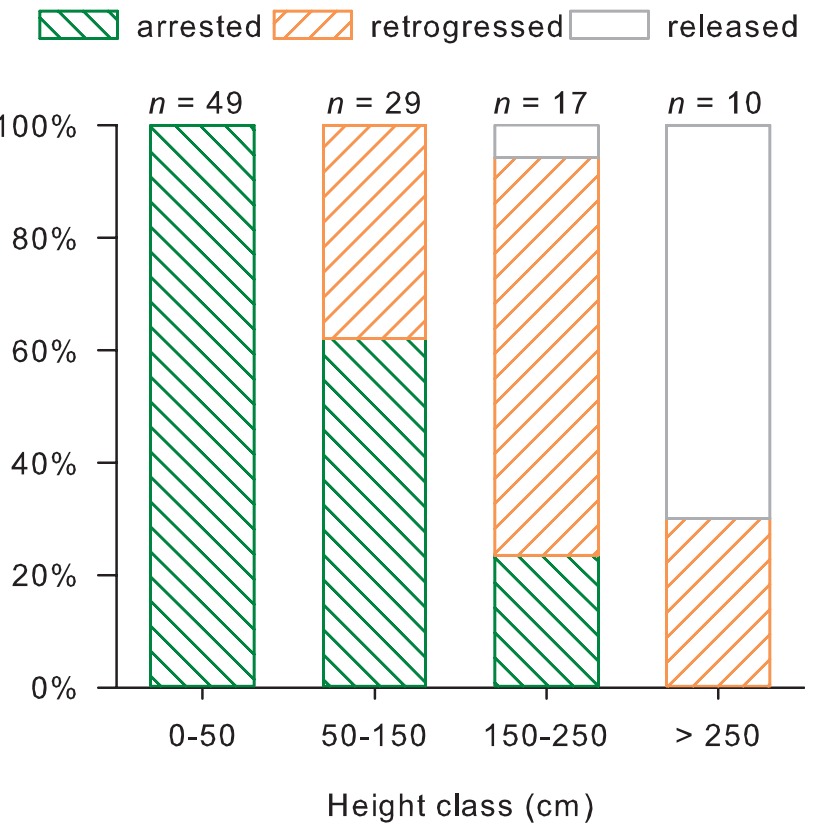

Figure 4. Dominant architecture types of willows, as in Keigley et al., ${ }^{1}$ pooled across all species present, for four height-classes at 39 sampling sites within the study area. As separate classifications were completed for each willow species encountered at each site, sample size $(n)$ represents the number of unique species and site combinations where a particular height class was present. The "uninterrupted" architecture type was not dominant for any of the four height classes for any species at any of the sampling sites. 

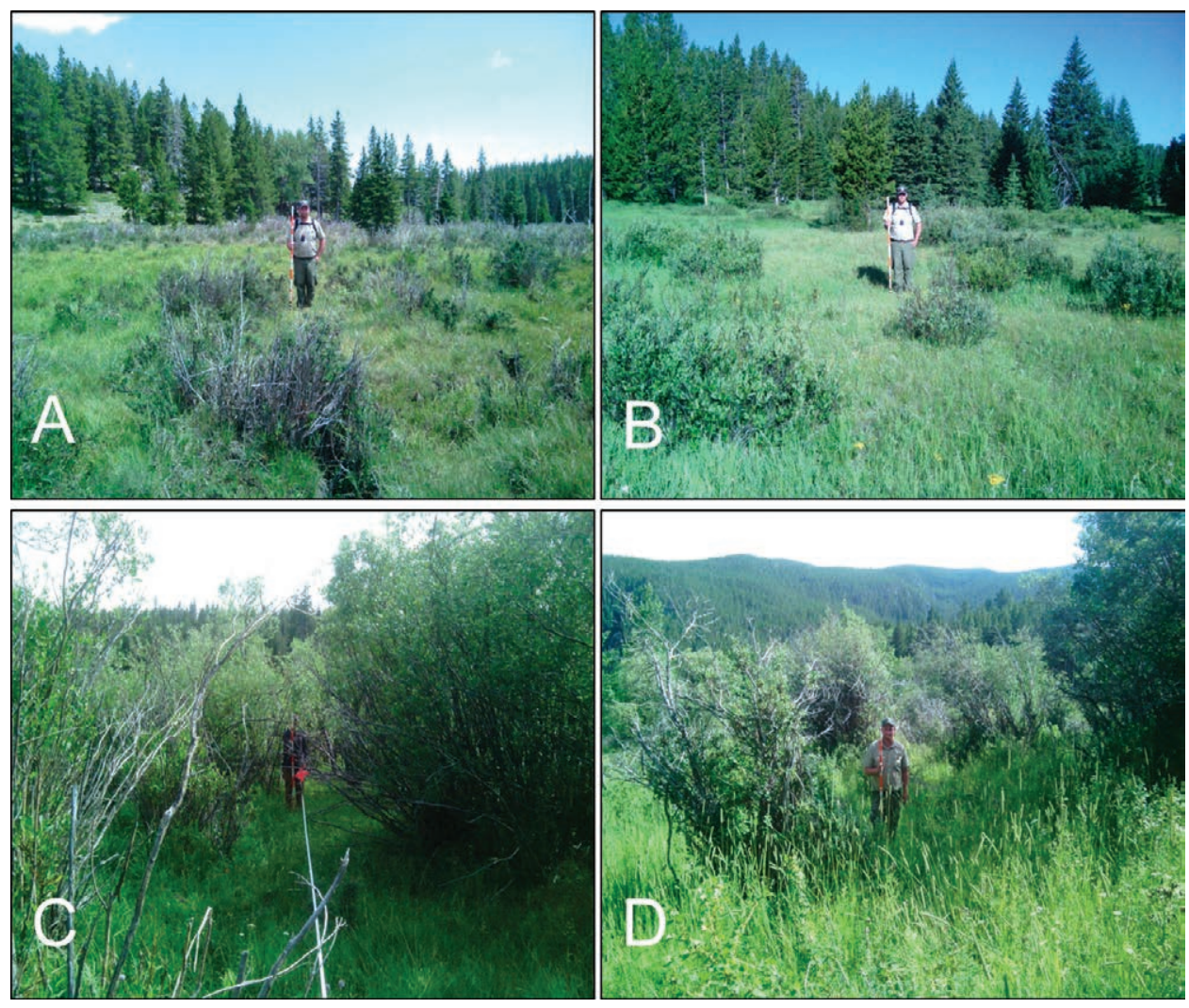

Figure 5. Examples of willow architecture types encountered during 2012 in our study area. Sites A and B are dominated by "arrested-type" architectures where their height was being suppressed. Sites $C$ and D include both "retrogressed-type" and "released-type" architectures. The taller plants at these two sites are characteristic of the released-type, having grown through the browse zone to attain their potential stature, presumably under different conditions than present currently. The shorter plants are characteristic of the retrogressed-type, typical of plants that initially gained height before being suppressed.

low (S. planifolia subsp. planifolia) with a growth potential of 1.83-3.05 $\mathrm{m}$ and planeleaf willow (S. planifolia var. monica), a short-growth variety with a growth potential of $0.61-1.52$ $\mathrm{m}$, which is more common above $2,732 \mathrm{~m}$ in elevation. In our characterization of dominant architecture types, we did not acknowledge this difference. As such, the architecture type of some plants may have been misclassified as arrested when, in fact, they had reached their height-growth potential. However, in determining dominant architecture types for individual plants, we relied on several indicators of browse intensity. In particular, where the majority of a plant's stems terminated in compact clusters of twigs, sometimes referred to as "clubbing," a plant was presumed to be prevented from growing toward its height potential by browsing and was classified as arrested or retrogressed. Furthermore, only three of our sampling sites (sites 11,12 , and 49) were above $2,732 \mathrm{~m}$ in elevation where the short-growth variety, planeleaf willow (var. monica), is more common. As a result, we feel it is unlikely that planeleaf willow (var. monica) were misclassified as the taller growth variety commonly enough to substantially influence our findings.

Although such architecture-type classifications should be considered a first step toward assessing browsing pressure, the consistency with which dominant architectures were classified as arrested and retrogressed for height classes most exposed to ungulate browsing (i.e., $100 \%$ of the time for height classes $<150 \mathrm{~cm}$ ) suggests browsing pressure is likely to be a significant factor affecting willow morphology in the study area. See Figure 5 for example photographs of common architecture types from the study area. To enable future comparisons, full results of architecture-type classifications, including sampling location details, are provided as online supplemental materials (Table S1; available at http://dx.doi. org/10.2111/Rangelands-D-14-00012.s1).

Among the 16 sites revisited in 2013, willows were absent from one site and mean LD index scores ranged from $-59 \mathrm{~cm}$ to $0 \mathrm{~cm}$ at remaining sites (Table 1 ). Most sites were dominated by plants with negative LD index values (13 of 15 sites) and existing browsing pressures of either $100 \%$ (14 sites) or 95\% (one site). Among all samples (i.e., individual plants), a single plant had a LD index score $>50 \mathrm{~cm}$; this plant was mechanically protected from browsing by dead fall. LD index scores less than zero typically correspond with shrubs that are dying back to ground level. ${ }^{3}$ As such, willow communities at the majority of the 15 sites appear to have recently lost height.

\section{Potential Constraints on Willow Height}

We propose two general explanations for the observed patterns of willow morphology and apparent constraints on 


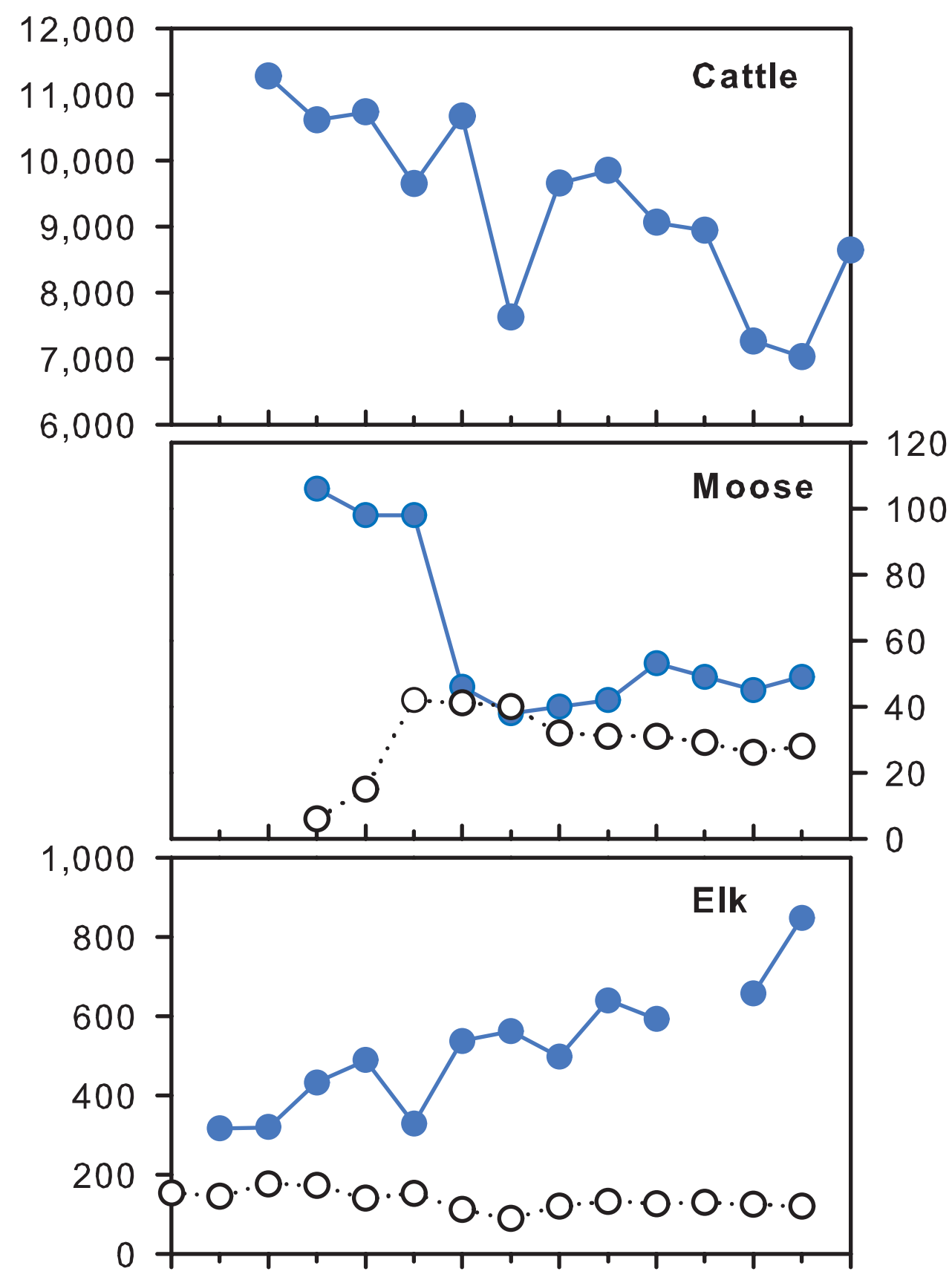

19982000200220042006200820102012

Figure 6. Recent authorized cattle use (animal-unit months), wild ungulate winter counts (solid points, lines), and hunter harvest (open points, dotted lines) during the period from 1998 to 2012 (x-axis) within the study area. Additional details regarding data sources are proved as online supplemental information (available at http://dx.doi.org/10.2111/Rangelands-D-14-00012.s1).

willow height growth. First, increasing ungulate abundance may have caused increasing browsing pressure, resulting in annual willow utilization in excess of annual production. Alternatively, reductions in willow growth or recruitment attributable to broad-scale factors such as changing climatic conditions may have reduced annual willow production, thus increasing utilization of remaining plants, even with a static ungulate population. Likewise, disturbances or disease out- breaks could directly reduce willow production through episodic stem mortality.

Increasing ungulate abundance has been commonly cited as a factor leading to willow declines, including in neighboring areas such as Yellowstone National Park ${ }^{5}$ and wildlife refuges in Montana. ${ }^{6}$ In our study area, the numbers of cattle, moose, and elk have changed in recent years (Fig. 4). The number of animal-unit months authorized for livestock graz- 


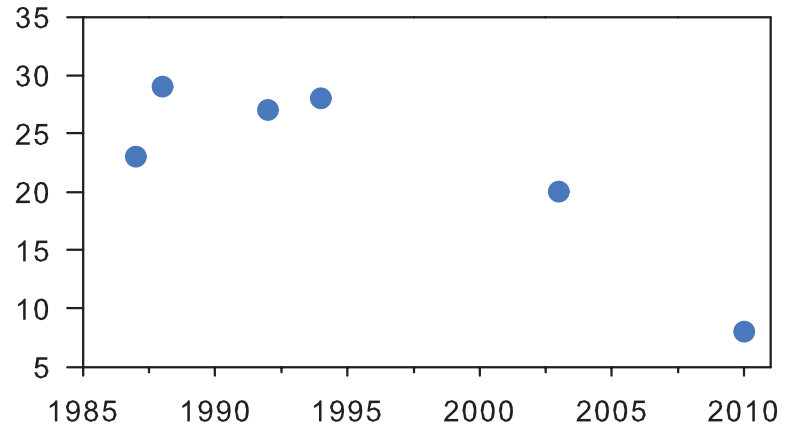

Figure 7. Results of periodic aerial beaver cache counts conducted across the study area during the period from 1985 to 2010. Data source: Wyoming Game and Fish Department. ${ }^{16}$ ing declined by 23\% from 2000 to 2012 (Mann-Kendall test statistic $\mathrm{S}=-52, P<0.01)$. Beginning in 2001, when the current aerial survey methods were adopted, the moose population appeared relatively stable until moose harvest was increased starting in 2003 which appears to have resulted in a $50 \%$ reduction in the moose population, though this decline was not statistically significant $(\mathrm{S}=-15, P=0.27)$. Winter elk count numbers from an area thought to best correspond to spring-fall use of the study area have increased by $168 \%$ since 1999 ( $\mathrm{S}=56, P<0.001)$. Assuming elk counts within this area are correlated with the magnitude of spring-fall elk herbivory within the study area, such an increase could help explain the observed constraints on willow height.

Table 1. Summary measures of browsing pressure from willows $(n=20)$ at 15 sites within the study area during 2013

\begin{tabular}{|c|c|c|c|c|}
\hline Site & $\begin{array}{c}\text { Mean } \mathbf{H}_{\mathrm{PYG}} \\
(\mathrm{cm})\end{array}$ & $\begin{array}{l}\text { Mean } H_{D} \\
\quad(\mathrm{~cm})\end{array}$ & Mean LD index \pm SE $(\mathrm{cm})$ & 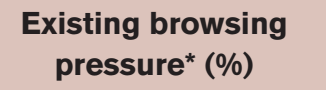 \\
\hline 3 & 23.10 & 26.25 & $-3.15 \pm 2.08$ & 100 \\
\hline 5 & 46.60 & 53.55 & $-6.95 \pm 7.37$ & 100 \\
\hline 6 & 64.95 & 83.00 & $-18.05 \pm 6.73$ & 100 \\
\hline 8 & 59.75 & 74.25 & $-14.50 \pm 4.05$ & 100 \\
\hline 10 & 28.45 & 28.40 & $0.10 \pm 2.18$ & 100 \\
\hline 11 & 33.30 & 37.80 & $-4.50 \pm 2.84$ & 100 \\
\hline 13 & 82.25 & 126.50 & $-42.75 \pm 12.19$ & 100 \\
\hline 15 & 32.90 & 63.80 & $-31.30 \pm 11.84$ & 100 \\
\hline 19 & 71.80 & 130.75 & $-58.95 \pm 12.4$ & 100 \\
\hline 23 & 26.50 & 55.00 & $-28.50 \pm 5.16$ & 100 \\
\hline 34 & 75.90 & 106.20 & $-30.30 \pm 9.57$ & 100 \\
\hline 35 & 16.70 & 19.75 & $-3.05 \pm 2.16$ & 100 \\
\hline 36 & 48.70 & 101.70 & $-53.20 \pm 12.02$ & 100 \\
\hline 45 & 88.15 & 119.70 & $-31.55 \pm 10.76$ & 95 \\
\hline \multicolumn{5}{|c|}{$\begin{array}{l}H_{P Y G} \text { indicates the height of the tallest stem to the base of the current year's growth; } H_{D} \text {, height to the tip of the tallest stem } \\
\text { having a dead, vertically oriented, complete annual increment that was browsed; and LD index, live-dead index, calculated } \\
\text { as } H_{P Y G}-H_{D} \text {. } \\
\text { * Existing browsing pressure indicates the percentage of samples at a site with an LD index score of }<50 \mathrm{~cm} \text {. }\end{array}$} \\
\hline
\end{tabular}


Isolating the effects of individual ungulates on the indicators of browsing pressure measured in our study is difficult for several reasons. First, any residual indirect effects of historic livestock grazing, such as remaining soil compaction, are poorly documented, but could also be affecting willow growth potential. Also, the effects of domestic livestock herbivory are likely to interact with those of wild ungulates in complex ways, making it difficult to isolate the contribution of a particular ungulate class to total willow browse. For example, a reduction in livestock stocking rates may result in additional upland forage for elk, reducing their use of riparian areas where willows occur. Given these complications, we recommend implementation of long-term willow monitoring to enable adaptive habitat management. Such monitoring should be based on an experimental design that controls for site potential and isolates the effects of individual ungulate species.

Additional factors warrant further consideration as potential explanations for the observed height constraints. The LD index was designed as an indicator of browsing pressure and a measure of how likely plants are to gain height following browsing. However, we cannot rule out the possibility that other factors contributed to mortality of measured stems. As such, LD index scores should be thought of as integrators of several potential sources of stem mortality (e.g., frost, disease, herbivory) that could affect plant height growth. During our study, we also observed large areas of willow dieback where taller stems have not been replaced by new growth (e.g., Fig. 1). Though this dieback could be explained by continued heavy browsing pressure that prevents replacement of taller branches that have died of old age, resulting in an accumulation of dead branches, ${ }^{1}$ a more episodic disturbance such as a potent frost event or disease epidemic could result in a similar level of stem mortality.

Interactions among factors are also likely to be important. For example, interactions among ungulate herbivory, other sources of stem wounding such as sapsucker damage, and fungal infections have been linked to willow diebacks in Rocky Mountain National Park. ${ }^{7}$ A preliminary survey in 2013 revealed the presence of these same potential factors within our study area (K. Kaczynski, personal communication, February 2014). Additional investigation is needed to understand the timing and causes of the observed willow dieback.

\section{Ecosystem Management Implications}

Whether the observed constraints on willow height have been caused by increasing ungulate abundance or by other factors affecting willow growth and recruitment, constraints on willow height could precipitate a variety of cascading ecosystem consequences. Although short willows provide some ecological benefits in terms of stream-bank stabilization and ungulate forage, other benefits are not realized until plants attain a greater height. Johnston et al. ${ }^{8}$ suggest that tall willows are more likely to support beaver colonies than shorter willows. The amount of shade cast by willows on streams, thereby reducing water temperatures for the benefit of coldwater-adapt- ed invertebrates and fishes, is a function of plant height. ${ }^{9}$ The availability of winter browse, a factor associated with moose abundance, ${ }^{10-12}$ is also affected by the ability of willow to gain sufficient height to extend above the winter snowpack.

Beyond the direct consequences of shorter plant height, sustained constraints on willow height can ultimately affect recruitment. Although height-suppressed willows may survive in the short term, their reproductive output could be diminished or eliminated, ${ }^{5}$ eventually resulting in declining willow distribution. For example, in their study of willow seed production in Yellowstone National Park, Kay and Chadde ${ }^{13}$ found that heavy browsing pressure by elk outside of exclosure fences suppressed willow height and entirely prevented seed production. Likewise, Gage and Cooper ${ }^{14}$ found evidence of reduced seed production in Rocky Mountain National Park resulting from heavy elk browsing. As we did not directly measure either rates of recruitment or willow reproduction, quantifying these vital rates should be a high priority for further work in order to understand the consequences of the observed height-growth constraints.

One case where further investigating the current status of riparian willows in terms of population vital rates and future distribution trends may be particularly important is in determining the cause of a recent decline in the abundance of beaver, a species designated as a management indicator species on the BNF. Since 1987, six aerial beaver cache counts have been completed for the southeast portion of the BNF by the Wyoming Game and Fish Department as an index of beaver abundance. Such cache counts have been promoted as the preferred beaver monitoring approach given their ease of implementation and the reliable 1:1 relationship between number of caches and number of beaver family units. ${ }^{15}$ The number of caches counted within our study area declined from a high of 29 in 1988 to eight in 2010 ( $72 \%$ decline) even though cache detection probability is likely to have increased over this period due to methodological adjustments ${ }^{16}$ (Fig. 5). Although many factors are known to affect beaver populations (e.g., timing and magnitude of stream flow, predator abundance, aspen availability), the constraints on riparian willows observed in our study could be affecting the availability of beaver forage and dam building materials, resulting in colony abandonment. Given the persistence of shifts in ecosystem state that have been observed elsewhere following beaver colony abandonment, management prescriptions that maximize willow seedling establishment and growth may be found to be needed to restore willow recovery potential.

\section{Acknowledgments}

We thank M. Barfield, J. Terry, K. Zacharkevics, K. Brown, and W. Shoemaker for assistance in the field. R. Keigley provided critical training and guidance in implementation of landscape-scale browse surveys. The efforts of D. Cooper and K. Kaczynski on the BNF and elsewhere continue to advance our understanding of factors affecting willow communities in the Rocky Mountain region. C. McClung, D. Beard, B. Bor- 
nong, and L. Walters-Clark helped support development and implementation of this and other efforts to better understand the status of riparian willows on the BNF. The manuscript was further improved by the thoughtful reviews of T. Cundy, S. Gall, C. Sergeant, an anonymous reviewer, and the editor.

\section{References}

1. Keigley, R. B., M. R. Frisina, and C. W. Fager. 2002. Assessing browse trend at the landscape level. Part 1: preliminary steps and field survey. Rangelands 24:28-33.

2. Keigley, R. B., M. R. Frisina, and C. W. Fager. 2002. Assessing browse trend at the landscape level. Part 2: monitoring. Rangelands 24:34-38.

3. Keigley, R. B., And M. R. Frisina. 2011. A process to monitor and manage browsing pressure, article 29. In: C. L. Wambolt, S. G. Kitchen, M. R. Frisina, B. Sowell, R. B. Keigley, P. Palacios, J. Robinson [compilers]. Proceedings-Shrublands: Wildlands and Wildlife Habitats; 17-19 June 2008; Bozeman, MT, USA. Available at: http://digitalcommons.usu.edu/nrei/vol16/iss1/29. Accessed 28 December 2012.

4. Girard, M., D. L. Wheeler, and S. B. Mills. 1997. Classification of riparian communities on the Bighorn National Forest. Denver, CO, USA: US Department of Agriculture, Forest Service, Rocky Mountain Region. R2-RR-97-02. 287 p. + appendices.

5. Singer, F. J., L. C. Mark, and R. C. Cates. 1994. Ungulate herbivory of willows on Yellowstone northern winter range. Journal of Range Management 47:435-443.

6. Keigley, R. B., J. Waren, and W.J. King. 2009. A multi-refuge program to evaluate the effect of ungulate browsing on habitat. Unpublished report. 186 p. Available at: http://digitalcommons.usu.edu/aspen_bib/7206/. Accessed 24 April 2011.

7. Kaczynski, K. M. 2013. Riparian willow decline in Colorado: interactions of ungulate browsing, native birds, and fungi [dissertation]. Fort Collins, CO, USA: Colorado State University. $111 \mathrm{p}$.

8. Johnston, D. B., D. J. Cooper, and N. T. Новbs. 2011. Relationships between groundwater use, water table, and recovery of willow on Yellowstone's northern range. Ecosphere 2(2):1-11.

9. Rutherford, J. C., S. Blackett, C. Blackett, L. Saito, and R. J. Davies-Colley. 1997. Predicting the effects of shade on water temperature in small streams. New Zealand Journal of Marine and Freshwater Research 31:707-721.
10. Stephenson, T. R., V. Van Ballenberghe, J. M. Peek, and J. G. MacCracken. 2006. Spatio-temporal constraints on moose habitat and carrying capacity in coastal Alaska: vegetation succession and climate. Rangeland Ecology \& Management 59:359-372.

11. Peek, J. M. 1974. On the nature of winter habitats of Shiras moose. Le Naturaliste Canadien 101:131-141.

12. Dorn, R. D. 1970. Moose and cattle food habits in southwest Montana. Journal of Wildlife Management 34:559-564.

13. Kay, C. E., ANd S. Chadde. 1992. Reduction of willow seed production by ungulate browsing in Yellowstone National Park. In: W. P. Clary, E. D. McArthur, D. Bedunah, and C. L. Wambolt [eds.]. Proceedings - Symposium on Ecology and Management of Riparian Shrub Communities; 29-31 May 1991; Sun Valley, ID, USA. Ogden, UT, USA: US Department of Agriculture, Forest Service, Intermountain Research Station. GTR INT-289. p. 92-99.

14. Gage, E. A., And D. J. Cooper. 2005. Patterns of willow seed dispersal, seed entrapment, and seedling establishment in a heavily browsed montane riparian ecosystem. Canadian Journal of Botany 83:678-687.

15. Beck, J. L., D. C. Dauwalter, D. M. Staley, and S. R. HirtzEL. 2008. Monitoring protocol for American beaver (Castor canadensis): examples from the Bighorn and Black Hills national forests. Revised May 2008. Unpublished report. Lakewood, CO, USA: US Department of Agricuture, Forest Service, Rocky Mountain Region, 74 p.

16. Wyoming Game and Fish Department. 2011. Beaver population study on the Bighorn National Forest. Sheridan, WY, USA: Wyoming Game and Fish Department. 20 p.

Authors are Forest Biologist, Michael_Bower@nps.gov (Bower), Wildlife Biologist (Decker), Fish Biologist/Hydrologist (Nowakowski), and Forest Hydrologist (Williams), Bighorn National Forest, Sheridan, WY 82801, USA. Present address (Bower): Southeast Alaska Network, National Park Service, Juneau, AK 99801, USA. Mention of a proprietary product does not constitute a guarantee or warranty of the product by USDA or the authors and does not imply its approval to the exclusion of the other products that also may be suitable. This work was supported by the US Forest Service Rocky Mountain Region and the Bighorn National Forest. 